Intecoms: Journal of Information Technology and Computer Science

Volume 2 Nomor 2, Desember 2019

e-ISSN : 2614-1574

p-ISSN : 2621-3249

DOI : https://doi.org/10.31539/intecoms.v2i2.927

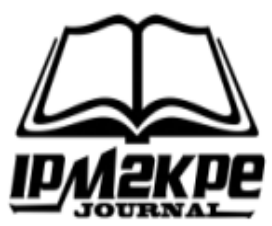

\title{
TEKNOLOGI NEAR FIELD COMMUCATION PADA PERPUSTAKAAN PERGURUAN TINGGI BERBASIS ANDROID
}

\section{NEAR FIELD COMMUNICATION TECHNOLOGY IN LIBRARY BASED ON ANDROID}

\author{
Muhammad Luthfi Hamzah ${ }^{1}$, Ermina Rusilawati ${ }^{2}$ \\ Sekolah Tinggi Ilmu Komputer Pelita Indonesia ${ }^{1,2}$ \\ luthfi.hamzah@lecturer.pelitaindonesia.ac.id ${ }^{1}$
}

\begin{abstract}
The library is a place that contains books, articles, papers and reading sources that are arranged as sources of information material. Therefore, with the rapid growth of technology, good management of library management is something that is very important for every college. One of the systems developed in this study is Near Field Communication (NFC) which is a subset of RFID (radio frequency identification). NFC is a technology that can simplify and facilitate transactions, transfer data, and wireless connections between two communication devices that are very close to a few centimeters. This system is designed using an Android device that has NFC technology. By using an NFC-based management system on an Android smartphone it is expected to improve its quality and be able to compete in the current technological era nationally or globally. The purpose of this study is to facilitate students in finding information sources by simply attaching an Android smartphone to the NFC tag attached to the book so as to obtain information about the book. This research method starts from discussing the discussion room, setting goals, discussing literature, analyzing problems, discussing models with UML, Designing systems, managing library information management and testing systems. Related to the completion of work in this study describes the design of library information management applications using Android-based Near Field Communication technology in Higher Education.
\end{abstract}

Keywords:Library, Near Field Commnication, RFID, Android.

\begin{abstract}
ABSTRAK
Perpustakaan merupakan suatu tempat yang berisikan buku, artikel, makalah dan sumber bacaan yang tersusun teratur sebagai sumber bahan informasi.Oleh sebab itu, dengan tumbuhnya teknologi dengan pesat, maka pengelolaan manajemen perpustakaan yang baik itu adalah sesuatu yang sangat penting bagi setiap perguruan tinggi.Salah satu sistem yang dikembangkan dalam penelitian ini adalah Near Field Communication (NFC) yang merupakan subset dari RFID (Radio frequency identification).NFC adalah teknologi yang dapat menyederhanakan dan memudahkan transaksi, pertukaran data, dan koneksi nirkabel antar dua perangkat komunikasi dengan jarak yang sangat dekat yaitu beberapa sentimeter.Sistem ini dirancang menggunakan perangkat smartphone Android yang mempunyai teknologi NFC.Dengan pemanfaatan sistem pengelolaan berbasis NFC pada smartphone Android ini diharapkan perguruan tinggi dapat meningkatkan kualitasnya dan mampu bersaing di era teknologi sekarang ini secara nasional maupun global. Tujuan dari penelitian ini agar dapat mempermudah mahasiswa dalam mencari sumber informasi dengan hanya menempelkan smartphone android pada tag NFC yang tertempel pada buku sehingga mendapatkan informasi tentang buku tersebut. Metode penelitian ini yaitu dimulai dari mengidentifikasi ruang lingkup, menentukan tujuan, mempelajari literatur, menganalisa masalah, merancang model dengan UML, Merancang sistem Pengelolaan manajemen informasi perpustakaan dan pengujian sistem.Adapun kerangka kerja pada metodologi penelitian ini menguraikan tentang rancang bangun aplikasi manajemen informasi perpustakaan dengan menggunakan teknologi Near Field Communication berbasis android di Perguruan Tinggi.
\end{abstract}

Kata Kunci :Perpustakaan, Near Field Communication, RFID, Android 


\section{PENDAHULUAN}

Perkembangan teknologi dan informasi sangat pesat dipengaruhi oleh tingginya kebutuhan dalam melakukan suatu kegiatan membutuhkan teknologi dan sistem informasi yang akurat, efektif dan efisien untuk mempermudah melakukukan aktivitas baik dalam sektor bisnis, sosial maupun di sektor pendidikan. Berkembangnya teknologi komputer mempengaruhi kinerja manusia sebagai operasional sistem sehingga peralihan ke arah sistem informasi yang berbasiskan komputer maupun smartphne semakin meningkat.

Di sektor pendidikan, diharapkan teknologi bisa membuat dan mempercepat dalam pengurusan administrasi perguruan tinggi, proses belajar mengajar maupun pengelolaan sarana dan prasarana perguruan tinggi tersebut. Salah satu fasilitas yang sangat vital di perguruan tinggi adalah perpustakaan. Oleh sebab itu perpustakaan harus dikelola dengan baik agar dapat mempermudah dosen dan mahasiswa menggunakan perpustakaan tersebut dengan maksimal karena merupakan pendukung dalam proses belajar mengajar.

Perpustakaan juga merupakan jantungnya suatu perguruan tinggi karena menunjang dalam pelaksanaan tri darma perguruan tinggi maka perlu pengelolaan manajemen perpustakaan yang baik agar dapat membantu mahasiswa dan dosen dalam mencari sumber informasi. Dan tentunya manajemen perpustakaan yang profesional sangat diperlukan dalam peningkatan kualitas perguruan tinggi.Untuk itu, perlu adanya suatu sistem yang membuat pengelolaan manajemen informasi perpustakaan dapat digunakan secara efektif dan efisiensi dari perubahan sistem manual ke sistem menggunakan teknologi.
Melihat betapa pentingnya sarana prasarana dalam peningkatan mutu perguruan tinggi, maka beberapa survey pendahuluan telah dilakukan di Perguruan Tinggi Pelita Indonesia Pekanbaru terkait dengan cara pengelolaan perpustakaan yang dilakukan. Dari hasil survei ditemukan beberapa hal sebagai berikut : 1) pengelolaan perpustakaan masih dilaksanakan secara manual yaitu dengan menggunakan catatan yang pada buku berukuran besar, 2) dikarenakan pengelolaan yang masih manual tersebut pendataan masing-masing perpustakaan sangat tidak efektif. Sebagai contoh tidak adanya data terkait informasi buku yang akan dipinjam melalui website maupun desktop, 3) perlu adanya sebuah sistem berbasis teknologi yaitu web dan smartphone yang memudahkan setiap orang melakukan Pengelolaan terhadap perpustakaan tersebut selain itu membuat kerja organisasi lebih efisien.

Berdasarkan dari beberapa permasalahan tersebut, sebuah perancangan teknologi ke atas pengelolaan perpustakaan perlu dilakukan. Teknologi yang umum digunakan dalam pengelolaan atau Pengelolaan adalah RFID (Radio frequency identification) yang merupakan sebuah sistem identifikasi frekuensi radio menggunakan tag, atau label yang melekat pada objek yang akan diidentifikasi. Teknologi terbaru dari RFID adalah Near Field Communication (NFC) karena NFC merupakan subset dari RFID yang mana teknologi ini mampu menyederhanakan maupun mempermudah transaksi, pertukaran data, dan koneksi nirkabel antar dua perangkat komunikasi dengan jarak yang sangat dekat yaitu jarak yang hanya beberapa sentimeter dengan 
prinsip induksi medan magnetic (Trivedi, 2015)

Tugas utama perpustakaan universitas adalah mendukung dalam proses pengajaran dan penelitian di bawah kurikulum masing-masing universitas. Secara umum, perpustakaan universitas sudah dipersiapkan dengan baik dalam hal sumber belajar, peralatan dan peralatan teknologi informasi, dan staff yang kompeten untuk menyediakan layanan informasi yang semuanya mendukung pembelajaran. Peserta didik di tingkat universitas umumnya siap dan tertarik untuk mempelajari hal-hal baru.Mahasiswa dapat berpikir, memahami, dan menjelaskan ide-ide abstrak secara efektif. Cara pembelajar pada tingkat ini menghabiskan waktu mereka mempengaruhi pembelajaran dan perkembangan mereka. Jika waktu dihabiskan untuk hal-hal yang berkaitan dengan bidang studi mereka, hasil akademik akan ditingkatkan. Secara umum, peserta senang bertemu dan berbicara dengan instruktur di luar kelas untuk mengajukan pertanyaan yang gagal mereka pahami, karena ini adalah waktu luang yang tidak akan mempengaruhi pembelajaran orang lain. Mereka juga dapat memperoleh pengetahuan di perpustakaan. Penelitian ini menjadi model untuk manajemen perpustakaan universitas akan menghasilkan sarana untuk mengembangkan perpustakaan universitas yang benar-benar mendukung pembelajaran mahasiswa berdasarkan informasi dari instruktur, administrator perpustakaan, dan pustakawan (Tuamsuk dkk, 2013).

Semua perpustakaan digital telah diubah secara cepat oleh peningkatan teknologi baru, berkembang dari sekadar mitra digital koleksi fisik perpustakaan umum dalam jaringan yang kompleks, mampu mendukung komunikasi dan kolaborasi di antara komunitas pengguna di seluruh dunia. Peningkatan ini menciptakan kebutuhan untuk sistem terintegrasi yang mampu mengelola perpustakaan digital dengan fungsi canggih yang saat ini belum terpenuhi. Barbuti, dkk mengusulkan arsitektur perpustakaan digital inovatif yang bertujuan menjembatani kesenjangan ini dengan fitur-fitur baru, seperti integrasi teknologi untuk memproses dokumen yang mencakup semua fase: akuisisi, ekstraksi konten, pengindeksan, pencarian, dan kesenangan. Sebuah sistem prototipe sedang dikembangkan dengan prospek yang sangat menarik yang akhirnya dapat mewujudkan model perpustakaan digital yang berfungsi sebagai sistem terpadu untuk preservasi, manajemen dan penggunaan objek digital multimedia yang kompleks (Barbuti dkk, 2014).

RFID di perpustakaan, dengan investasi sederhana, dapat meningkatkan kemampuan pustakawan dan pengguna. Penggunaan baru RFID di perpustakaan untuk membantu menentukan lokasi fisik buku di dalam perpustakaan dan untuk memberikan bantuan kepada pengguna untuk tiba di lokasi yang diinginkan. Aplikasi ini terdiri dari tiga sistem utama: yang elektronik - yang mendeteksi pengguna sistem RFID; sistem berbasis AI untuk merencanakan dan memantau pengguna sesuai dengan minat mereka; dan terakhir sistem informasi berbasis visual yang visualisasi yang harus diikuti pengguna. Kami telah mengembangkan sistem komunikasi dengan menggunakan teknologi Zigbee untuk memungkinkan keduanya, arus informasi untuk RFID.Ini menghilangkan kebutuhan untuk menggunakan kabel. Aplikasi ini tidak hanya membantu pengguna untuk dengan mudah menemukan buku-buku 
atau ruang baca di dalam gedung, tetapi juga mengotomatiskan tugas yang dilakukan secara manual oleh staf perpustakaan yaitu menghasilkan statistik tentang waktu menggunakan buku, penggunaan terkait, dan lainnya (R-Moreno dkk, 2014). Selain pengelolaan manajemen perpustakaan yang banyak digunakan menggunakan web maupun desktop, saat ini Teknologi Augmented reality pada seluler telah mendapatkan popularitas dalam beberapa tahun terakhir karena kemajuan teknologi smartphone dan perangkat seluler lainnya. Salah satu bidang tertentu di mana augmented reality seluler digunakan adalah manajemen perpustakaan (Shatte, dkk., 2014; Aryanto \& Irianto, 2013; Fatmawati, 2015).

Kebanyakan smartphone sekarang dilengkapi dengan beberapa sensor yang dapat digunakan untuk meningkatkan dan membuat pengguna antarmuka baru. Ini adalah kasus untuk kamera terintegrasi yang dapat digunakan untuk membaca kode visual, seperti Quick Response (QR) Code serta teknologi penginderaan lainnya seperti Radio Frequency Identification (RFID) dan Near Field Communications terkait (NFC). Penggunaan Kode QR dan tag RFID telah berkembang secara signifikan dalam dekade terakhir, mereka pertama kali digunakan untuk melacak produk di industri, tapi sekarang mereka telah memberikan kontribusi untuk mengembangkan beberapa konsep baru yang mengintegrasikan dunia fisik dengan satu virtual (Briseno, 2012). RFID adalah metode Automatic Identification and Data Capture (AIDC) yang menggunakan gelombang radio untuk menyimpan dan mengambil data dari chip identifikasi. Chip ini dikenal sebagai tag RFID. RFID sekarang banyak digunakan di industri untuk beberapa aplikasi termasuk keamanan, kontrol akses, transportasi dan Pengelolaan rantai pasokan. Biasanya sistem RFID memerlukan tiga komponen utama: reader / writer, tag RFID dan aplikasi perangkat lunak untuk pengolahan informasi (Rismawati, 2016).

Sebuah perangkat mobile $N F C$ enabled harus memiliki hardware yang sesuai, itu termasuk satuan frekuensi radio, prosesor baseband dan Controller NFC dengan antena. Ini juga termasuk sebuah chip smartcard aman dikenal sebagai elemen aman yang dapat digunakan untuk modetag emulasi yang memungkinkan perangkat mobile untuk digunakan sebagai kartu pintar. Ini berarti bahwa ponsel NFC-enabled dapat beroperasi dalam mode berikut seperti yang digambarkan pada gambar dibawah ini (Briseno, 2012): 1) mode Emulasi Kartu. Pada mode emulasi kartu di mana perangkat NFC berperilaku dengan cara yang sama sebagai tag daripada generator lapangan. Mode ini digunakan untuk memungkinkan pembayaran contactless, di mana media pembayaran menggunakan telepon hanya melambaikan dekat perangkat penerima untuk memulai transaksi, 2) mode Pembaca / Penulis NFC. Pada mode ini, induk NFC dapat membaca / menulis tag NFC. Contohnya adalah membaca informasi berguna dari poster pintar, 3) mode Peer To Peer

Sebuah perangkat yang dilengkapi NFC dapat digunakan sebagai modus Peer-to-Peer dengan memungkinkan dua pengguna untuk bertukar informasi antara perangkat mereka seperti playlist musik, kontak, dan bahkan data medis.

Ada empat kategori bagaimana cara NFC bekerja Al-Ofeishat \& Rababah (2012) yaitu: 1) telepon ke telepon, 2) telepon ke perangkat, 3) telepon ke tag, 4) telepon untuk 
pembaca (reader)

Teknologi NFC ini juga digunakan dalam sistem tiket pengindraan biokimia, pariwisata, pembayaran via mobile dan bidang lainnya yang dapat mempermudah dan mempercepat proses transaksi data dengan jarak yang sangat dekat (Zupanovic, 2015; Xu, dkk, 2017; Pesonen\& Horster, 2012; Mainetti, dkk., 2012).

\section{METODE PENELITAN}

Adapun metode penelitian dalam penelitian ini menggunakan metode waterfall yaitu metode air terjun yang mana setiap langkah harus diselesaikan sampai tuntas baru bisa masuk ke langkah selanjutnya, berikut ini adalah langkah-langkah dalam penelitian ini, yaitu :

\section{Identifikasi Ruang Lingkup}

Pada tahap ini penulis melakukan identifikasi terhadap ruang lingkup penelitian yang bertujuan untuk menjaga konsistensi dari penelitian ini sehingga penelitian ini lebih terarah dan tercapinya tujuan dari penelitian yang diharapkan. Dalam mengidentifikasi ruang lingkup ini penulis menetapkan batasan masalah yang akan dipecahkan. Dalam hal ini berupa pemodelan UML untuk perancangan sistem pengelolaan perpustakaan menggunakan teknologi NFC berbasis Android.

\section{MenentukanTujuan}

Setelah membatasi ruang lingkup dan perumusan masalah dalam topik yang diteliti, tahap selanjutnya yaitu menentukan kerangka tujuan terhadap penelitian yang dilakaukan. Di mana tujuan dari penelitian ini adalah bagaimana merancang model UML untuk untuk perancangan system pengelolaan perpustakaan menggunakan teknologi NFC berbasis Android.

\section{Mempelajari Literatur}

Langkah selanjutnya adalah mempelajari literatur-literatur agar dapat diseleksi untuk dapat ditentukan literature mana yang akan digunakan dalam penelitian ini. Sumber literatur didapatkan dari jurnal, artikel, yang membahas tentang manajemen perpustakaan, smartphone, Android, NFC dan bahan bacaan lain yang mendukung penelitian.

\section{Analisa Masalah}

Analisa masalah dilakukan untuk dapat memahami masalah yang telah ditemukan pada penelitian lapangan. Dengan menganalisa masalah tersebut, maka diharapkan masalah dapat dipahami dengan baik sehingga dapat ditentukan langkah penyelesaiannya. Masalah yang dimaksud adalah bagaimana merancang dan membangun sebuah aplikasi android untuk melakukan pengelolaab kepada sarana prasarana perguruan tinggi.

\section{Pengumpulan Data}

Setelah menganalisa masalah, maka langkah selanjutnya adalah mengumpulkan data-data yang diperlukan untuk pembuatan rancang bangun sistem pengelolaan sarana prasarana dengan menggunakan teknologi NFC berbasis Android.

\section{Perancangan Model}

Setelah didapatkan analisa terhadap masalah dilakukan. Langkah selanjutnya yaitu menuangkan permasalahan tersebut ke dalam bentuk model UML. Model UML nantinya akan dipergunakan lebih lanjut dalam membangun aplikasi dalam pengelolaan sarana prasarana perguruan tinggi dengan menggunakan NFC berbasis android (Maita \& Adawiyah, 2017). 


\section{Perancangan Sistem}

$\begin{array}{lrr}\text { Hasil dari perancangan model } \\ \text { diatas } & \text { selanjutnya akan }\end{array}$ diimplementasikan ke dalam perancangan sistem pengelolaan sarana prasarana. Dalam hal ini, sistem yang dimaksud adalah aplikasi pembelajaran berbasis android. Perancangan ini nantinya akan dibuat sesuai dengan menggunakan teknologi NFC pada android menggunakan bahasa JAVA dengan bantuan software Android Studio sehingga aplikasi ini bisa berjalan lancar di smartphone berbasis android.

\section{Pengujian Sistem}

Sistem yang telah dirancang di atas selanjutnya diuji untuk melihat sejauh mana sistem yang dibangun telah sesuai dengan yang diharapkan.

\section{Implementasi}

Sistem yang bangun di implementasikan pada perpustakaan perguruan tinggi pelita indonesia.

\section{Evaluasi}

Setelah

diimplementasi

kemudian di evaluasi untuk dapat mengetahui kekurangan dan keefektivitas, keefisien dan kepraktisan program yang buat.

\section{Launching Produk}

Peluncuran produk setelah dievaluasi agar tidak ada kekurangan dan dapat digunakan seterusnya

\section{HASIL DAN PEMBAHASAN Analisa Hadware NFC Tag}

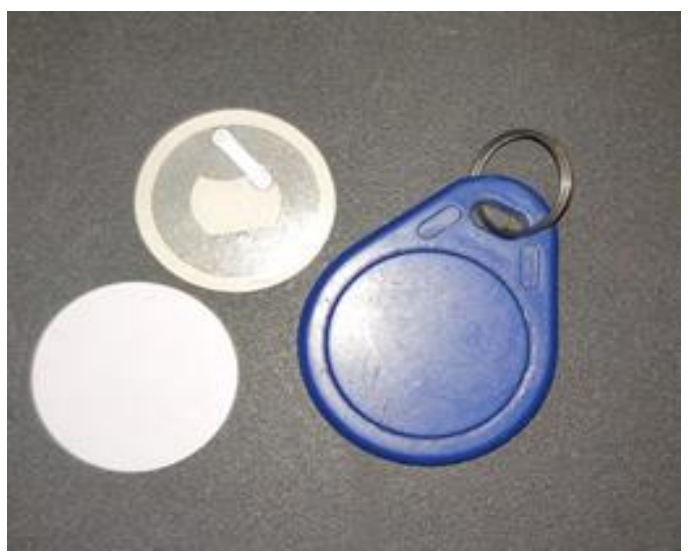

Gambar. 1 NFC Tag

NFC telah dikembangkan oleh NXP® Semiconductor sebagai IC tag NFC standar untuk digunakan untuk ritel, game, konsumen dan lainnya. Pada penelitian ini nfc yang digunakan adalah NTAG 216 dengan spesifikasi 888 bytes user memory dengan URL lengthnya 854 karakter dan text lenghtnya 852 karakter.

\section{Tampilan NFC Tag pada Buku}

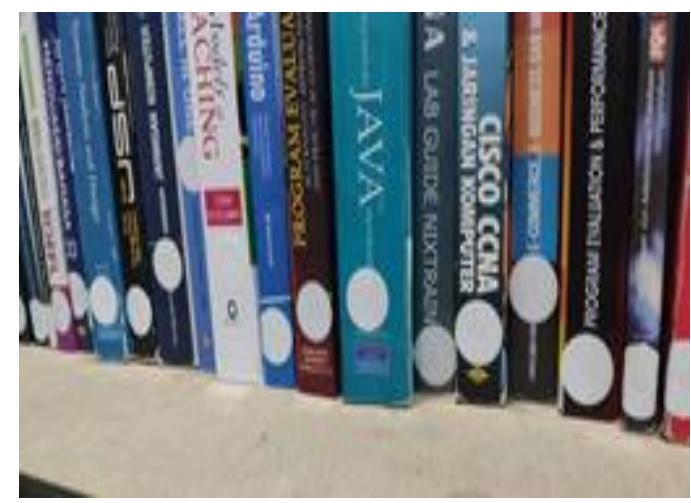

Gambar 2. Buku yang telah di tempel NFC Tag

Setiap buku di perpustakaan ditempelkan nfc tag ini di bagian belakang buku sehingga nantinya akan memudahkan mahasiswa untuk menempelkan smartphone nya untuk mengetahui informasi dengan cepat terkait buku yang akan dipinjamnya. 
Analisa Sistem

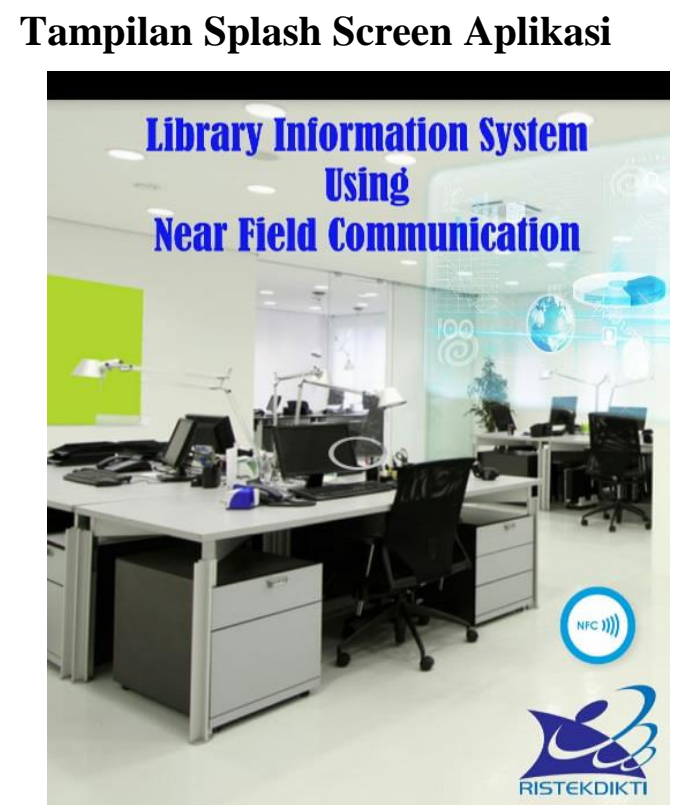

Gambar. 3 Splash Screen Aplikasi

Tampilan Spash Screen ini adalah tampilan awal ketika membuka aplikasi ini.

\section{Tampilan Utama Aplikasi}

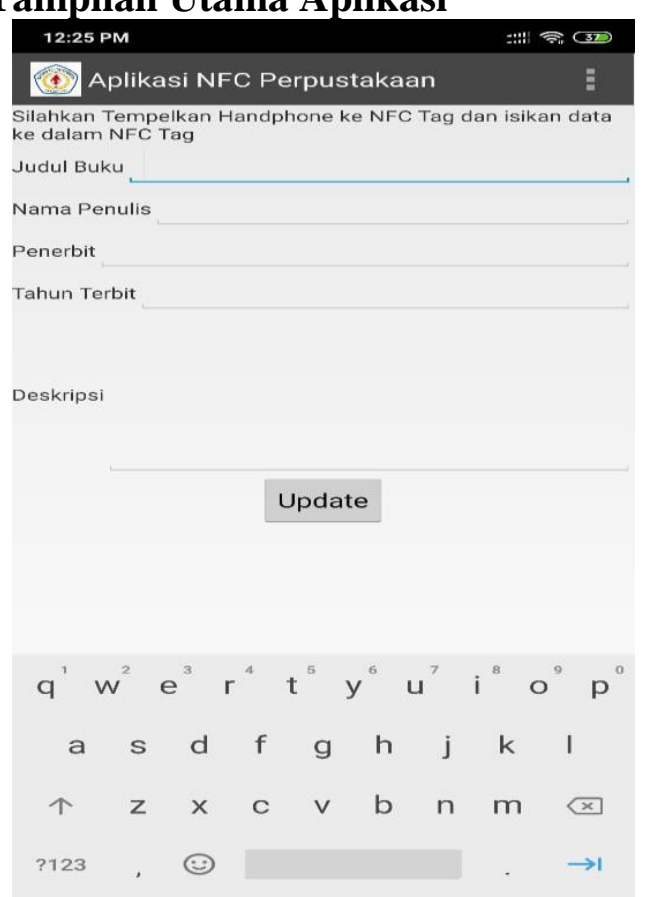

Gambar. 4 Tampilan Utama

Pada tampilan ini berisikan inputan data-data yang akan dimasukkan ke dalam NFC tag.

\section{Tampilan Input Data}

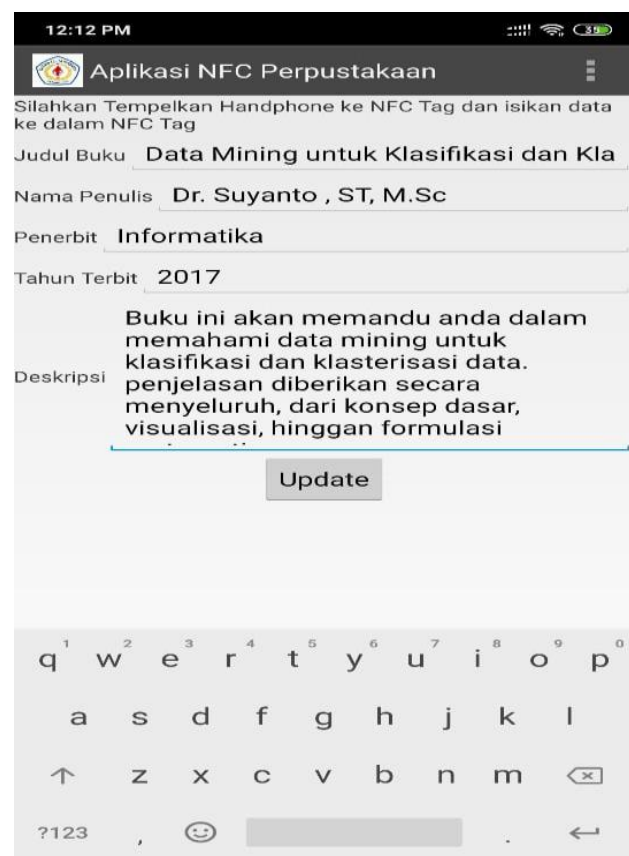

Gambar. 5 Input Data Buku

Pada tampilan ini merupakan tampilan untuk memasukkan data ke dalam NFC tag dengan cara menempelkan smartphone ke NFC tag yang akan di isi datanya.

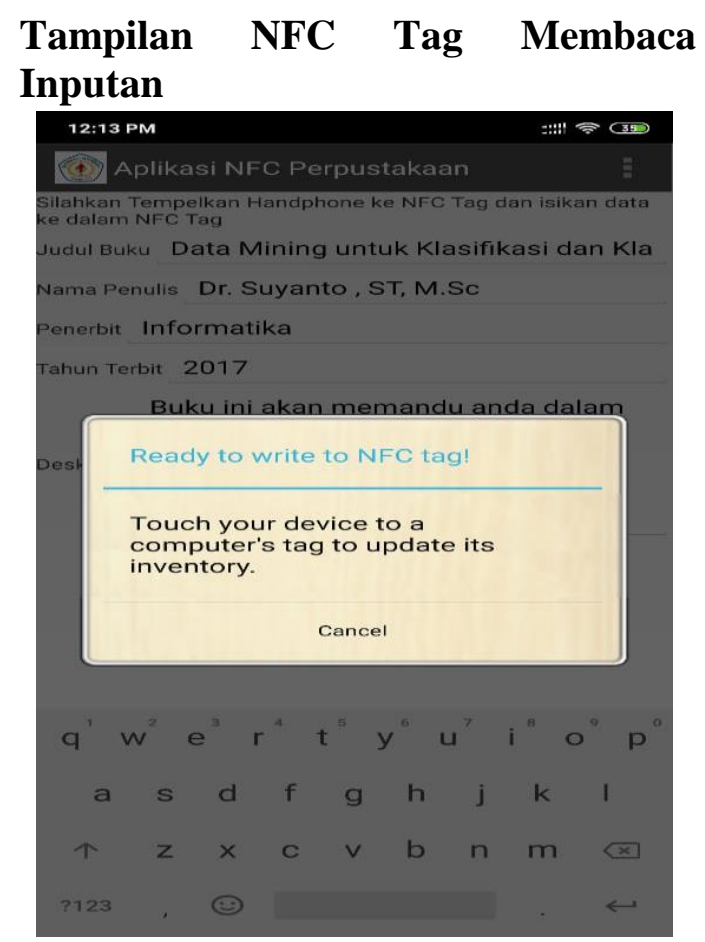

Gambar. 6 Tampilan Input Data ke NFC Tag 
Pada tampilan ini merupakan tampilan yang memberitahu agar segera menempelkan smartphone ke NFC tag untuk mentransfer data yang diinput.

\section{Tampilan Membaca dan Update Data pada NFC Tag}

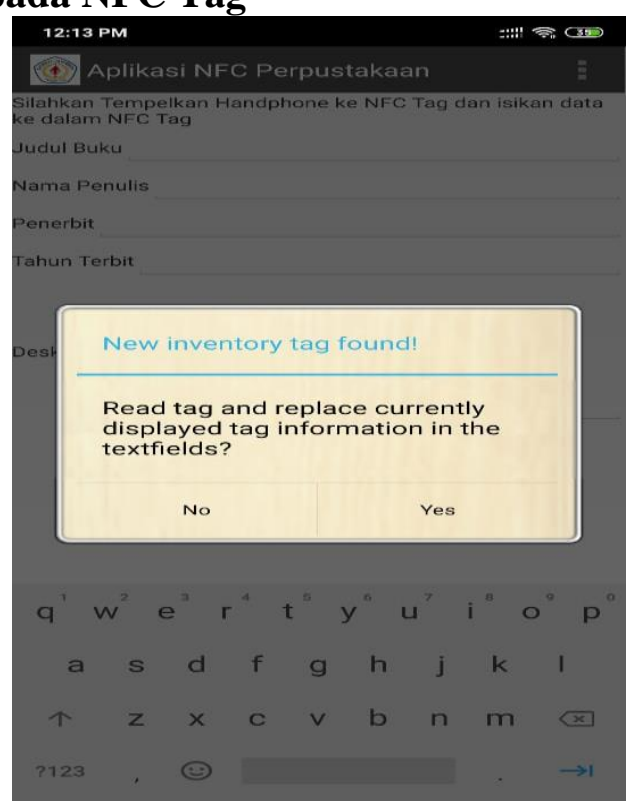

Gambar. 7 Membaca NFC Tag pada Buku

Pada tampilan ini adalah pemberitahuan yang muncul ketika smartphone didekatkan dengan NFC tag pada buku di perpustakaan untuk membaca datanya dan juga dapat memperbaharui data nfc tag yang ada pada buku tersebut.

\section{SIMPULAN}

Penggunaan Teknologi NFC berbasis android ini mempermudah mahasiswa, dosen dan staff perpustakaan dalam pencarian informasi terkait buku sebelum melakukan peminjaman. Mereka hanya menempelkan smartphone pada bagian buku yang ada nfc tagnya.

\section{DAFTAR PUSTAKA}

Al-Ofeishat, H. A., \& Rababah, M. A. A. (2012). Near Field

Communication International Journal of Computer Science and Network Security, 12(2), 93-99

Aryanto, A. \& Irianto, T. (2013). Pembuatan Sistem Informasi Perpustakaan SMP Muhammadiyah 7 Surakarta. Journal Speed-Sentra Penelitian Engineering dan Edukasi, 5(1), 15-20

Barbuti, N., Ferilli, S., Redavid, D., \& Caldarola, T. (2014). An Integrated Management System For Multimedia Digital Library. Procedia Computer Science, 38(2014), 128-132

Briseno, M. V., Hirata, F. I., Lopez, J. D. S., Garcia, E. J., Cota, C. N., \& Hipolito J. I. N. (2012). Using RFID/NFC and QR-Code in Mobile Phones to Link the Physical and the Digital World. Interactive Multimedia. Mexico: University of Baja California

Fatmawati, E. (2015). Technology Acceptance Model (TAM) untuk Menganalisis Penerimaan terhadap Sistem Informasi Perpustakaan. Jurnal Iqra', 9(1), 1-13

Mainetti, L., Patrono, L. \& Vergallo, R. (2012). IDA-Pay: A Secure and Efficient Micro-Payment System Based on Peer-to-Peer NFC Technology for Android Mobile Devices. Journal of Communications Software and System, 8(4), 117-125

Maita, I. \& Adawiyah, A. (2017). Sistem Informasi Reservasi Online pada Guest House UinSuska Riau Berbasiskan Web. Jurnal Ilmiah Rekayasa dan Manajemen Sistem Informasi, 
3(1), 85-96

Pesonen, J. \& Horster, E. (2012). Near Field Communication Technology in Tourism. Tourism Management Perspectives, 4, 11-18

R-Moreno, M. D., Castano, B., Barrero, D. F. \& Hellin, A. M. (2014). Efficient Services Management in Libraries using AI and Wireless Techniques. Expert System with Applications, 41, 7904-7913

Rismawati, N. (2016). Sistem Absensi Dosen Menggunakan Near Field Communication (NFC) Technology. Fakultas Teknik, Matematika dan Ilmu Pengetahuan Alam. Universitas Indraprasta PGRI. Jurnal Faktor Exacta Vol 9(2), 135-142

Shatte, A., Holdsworth, J., \& Lee, I. (2014). Mobile Augmented Reality Based Context-Aware Library Management System. Expert System with Applications, 41, 2174-2185

Trivedi, D. (2015). Near Field Communication: Overview and Applications. India. International Journal of Engineering Development and Research (IJEDR), 3(3), 1-12

Tuamsuk, K., Kwiecien, K., \& Sarawanawong, J. (2013). A University Libraby Management Model for Students' Learning Support. The International Information \& Library Review, 45, 94-107

Xu, G., Zhang, Q., Lu, Y., Liu, L., Ji, D., Li, S. \& Liu, Q. (2017). Passive and Wireless Near Field Communication Tag Sensors for Biochemical Sensing with Android. Sensors and Actuators B: Chemical, 246, 748-755
Zupanovic, D. (2015). Implementation Model for Near Field Communication in Croation Ferry Ticketing System. Procedia Engineering, 100, 1396-1404 